\title{
Registrars teaching undergraduate medical students: A pilot study at the University of Pretoria, South Africa
}

L du Toit-Prinsloo, ${ }^{1}$ MB ChB, DipForMed (SA) Path, FCForPath (SA), MMed (Path) (Forens); N K Morris, ${ }^{1}$ BSc, BSc Hons, MSc (Medical Criminalistics); M Lee, ${ }^{2}$ BBibl Hons; G Pickworth, ${ }^{3}$ BSc, BSc Hons (Psych), MEd (Psych), DPhil (Psych)

${ }^{1}$ Department of Forensic Medicine, Faculty of Health Sciences, University of Pretoria, South Africa

${ }^{2}$ Department of Library Services, Faculty of Health Sciences, University of Pretoria, South Africa

${ }^{3}$ Department of Education Innovation, Faculty of Health Sciences, University of Pretoria, South Africa

Corresponding author: $L$ du Toit-Prinsloo (lorrainedutoitprinsloo@gmail.com)

Background. Registrars play a vital role in teaching undergraduate (UG) medical students. Previous studies indicate that registrars contribute as much as $30 \%$ of medical students' knowledge and that up to $20 \%$ of a registrar's time is spent on teaching UG medical students. The Association for Medical Education in Europe (AMEE) Guide No. 20 defines 12 roles of a teacher, including an on-the-job role-model.

Objective. To evaluate the perception and attitudes of registrars with regard to their role as teachers of UG medical students.

Methods. A questionnaire-based study with qualitative and quantitative aspects was conducted at the Faculty of Health Sciences, University of Pretoria, South Africa.

Results. Despite numerous attempts, the response rate to the study was very poor, with only 25 registrars participating. This pilot study indicated that registrars were mostly involved with on-the-job training, followed by ward rounds and practical sessions. The attitudes towards teaching included that registrars deemed teaching as beneficial, with only three indicating that it should not be done by registrars. Advantages of teaching included own learning opportunities and gaining confidence in teaching. Registrars' own workload and lack of time hampered teaching. The majority of registrars indicated that receiving training with regard to teaching would be useful.

Conclusion. Our pilot study concurs with international studies, indicating that the benefits of teaching medical students include knowledge acquired by registrars. Studies showed that the knowledge obtained in this manner outweighed that obtained by self-study/attendance of lectures. The on-the-job role-model as part of teaching is applicable to registrars. The international literature indicates that until recently registrars were not offered a formal teaching programme. Our study echoed this, with only one student indicating that it is not necessary, as registrars should not be expected to teach.

Afr J Health Professions Educ 2016;8(2):196-199. DOI:10.7196/AJHPE.2016.v8i2.660

The Health Professions Council of South Africa (HPCSA) is the overall governing body of the medical and dental profession in SA. The vision of the HPCSA is 'to enhance the quality of health by developing strategic policy frameworks for effective co-ordination and guidance of our twelve Professional Boards in: Setting healthcare standards for training and discipline in the professionals registered with the HPCSA: ${ }^{[1]}$ The HPSCA, in conjunction with the SA government, set high standards and rules with regard to the training of undergraduate (UG) medical students. The SA Medical and Dental Council regulations relating to the registration of students, minimum curricula and professional examinations in medicine and dentistry (R652, May 1995) clearly stipulate the minimum curriculum requirements for medical studies in part II of the regulations. ${ }^{[1]}$ It is well known that at different medical schools in SA, registrars (also known as residents in other countries) are involved in the training of UG medical students. ${ }^{[2]}$ The HPSCA, however, does not indicate the role of the registrar as teacher. There seems to be a paucity of literature pertaining to the exact extent of UG training that registrars conduct. ${ }^{[2]}$ The majority of studies relating to the role of registrars as teachers have been conducted in the northern hemisphere.

Registrars play a vital role in teaching UG medical students. A review article by Post et al. ${ }^{[3]}$ specifically researched the role of registrars in teaching clinical skills. It is stated that registrars contribute to as much as $30 \%$ of medical students' knowledge, and studies indicate that up to
$20 \%$ of a registrar's time is spent on teaching UG medical students. ${ }^{[4-8]}$ The benefits of teaching medical students are also seen in the knowledge acquired by registrars. A study by Weiss and Needlman ${ }^{[9]}$ showed that by teaching UG students residents improved their own knowledge and understanding of the topic. The knowledge obtained from teaching outweighed that obtained by self-study or attendance of lectures. ${ }^{[9]}$

The Association for Medical Education in Europe (AMEE) Guide No. 20 defines 12 roles of a teacher, which include a teacher being someone who provides information, and who is a role-model, facilitator, assessor and planner. ${ }^{[10]}$ The section on a role-model specifically refers to an on-thejob model during contact sessions with students. ${ }^{[10]}$ This is applicable to registrars, as they spend much of their time with the UG students during ward rounds and on-call sessions. Mentorship is regarded as part of the role of facilitator, and the role of mentor is inevitable. ${ }^{[10]}$ Clinical and practical training form part of providing information. ${ }^{[10]}$ Norcini and Burch $^{[11]}$ emphasised the importance of assessment in the workplace, including presentation of clinical findings after students conducted the physical examination of patients. This is also applicable to registrars, as UG students present their findings after examination of the patient. The article also stresses the importance of providing feedback to students after the assessment. $^{[11]}$

The international literature indicates that, until recently, residents were not offered a formal programme in teaching. Morrison et al. ${ }^{[12]}$ in the USA, 
indicated that 'by $2000,55 \%$ of US residencies provided instruction on teaching, but those who provided such instruction only did so for 11 hours per resident for the entire residency.

Smit ${ }^{[2]}$ conducted a study at Stellenbosch University, SA, reviewing the role of the registraras-a-teacher. Her findings indicated that registrars spent $40 \%$ of their time teaching UG medical students and that only one of the registrars had received formal training in teaching. At the University of Pretoria (UP), SA, registrars play a vital role in teaching UG medical students. No research has been done at our university to indicate the extent and type of training, involvement of registrars in the assessment of UG students, and the registrars' perceptions about their role as teachers. UP provides a Medical Education Orientation Programme (MEOP), which assists in equipping teachers with basic knowledge to teach UG students. This programme is, however, not compulsory for registrars.

The objective of this study was to evaluate the current involvement of registrars as teachers of UG medical students, including reviewing how much time a registrar spends on teaching such students, the type (and duration) of teaching being done, involvement in assessment of students, their perceptions regarding their role as teachers, and whether a need exists for training registrars as teachers.

\section{Methods}

A questionnaire-based study with qualitative and quantitative aspects was conducted at the Faculty of Health Sciences, UP. All registrars enrolled at UP were identified and the questionnaires were distributed with the help of the secretary of the head of the department. The data collected included the following:

- demographic details (age, gender)

- type of discipline (surgery/medicine/pathology)

- current year as registrar

- indication of the average working hours per week
- different types of teaching provided and time spent on teaching

- attitude towards teaching medical students

- constraints in teaching medical students

- need for a formal teaching course

- involvement in assessing UG medical students

- competency table.

The study was approved by the Faculty of Health Sciences Research Ethics Committee, UP. Data were analysed using Epi Info 7 (CDC, USA).

\section{Results}

Despite numerous reminders and resending of the questionnaires, only 25 of the initial 280 questionnaires distributed were returned (response rate 9\%). These results are therefore only a pilot study of the attitudes of registrars.

\section{Demographic details}

Registrars were aged between 28 and 44 years, with the majority $(n=18 ; 72 \%)$ between 30 and 35 years. There were 15 females and 8 males (2 did not indicate gender). Eight registrars (35\%) were in a surgical discipline, $4(17 \%)$ in a medical discipline, 7 (31\%) in pathology, and $4(17 \%)$ in dentistry. The average number of hours worked per week was stated as 54 .

\section{Teaching done by registrars}

Table 1 indicates the type of teaching done by registrars and the average time spent on teaching. Most of the registrars' teaching was so-called on-the-job training ( 5 hours 4 minutes per week).

\section{Views/attitudes of registrars towards teaching}

The registrars indicated the following views/ attitudes towards their role as teachers of UG medical students:

- enjoy teaching $(n=9)$

- it is a duty $(n=5)$

- day-time teaching should be done by consultants and after-hours teaching by registrars $(n=1)$

Table 1. Type of teaching and time spent on teaching by registrars

\begin{tabular}{|c|c|c|c|c|c|}
\hline Type of teaching & Time spent per week & $\begin{array}{l}\text { Yes, } \\
n(\%)\end{array}$ & $\begin{array}{l}\text { No, } \\
n(\%)\end{array}$ & $\begin{array}{l}\text { Not applicable, } \\
n(\%)\end{array}$ & $\begin{array}{l}\text { Respondents, } \\
n\end{array}$ \\
\hline Formal lectures & $1 \mathrm{~h} 9 \mathrm{~min}$ & $11(46)$ & $12(50)$ & $1(4)$ & 24 \\
\hline Tutorials & $1 \mathrm{~h} 45 \mathrm{~min}$ & $14(56)$ & $10(40)$ & $1(4)$ & 25 \\
\hline Ward rounds & $2 \mathrm{~h} 40 \mathrm{~min}$ & $16(64)$ & $8(32)$ & $1(4)$ & 25 \\
\hline Practical sessions & $1 \mathrm{~h} 52 \mathrm{~min}$ & $12(48)$ & $12(48)$ & $1(4)$ & 25 \\
\hline On-the-job training & $5 \mathrm{~h} 4 \mathrm{~min}$ & $12(48)$ & $12(48)$ & $2(8)$ & 25 \\
\hline
\end{tabular}

- it is important and refreshes one's knowledge $(n=5)$

- negative feeling $(n=4)$

- should not be done by registrars $(n=1)$

- stressed out $(n=1)$.

\section{Benefits of teaching}

The benefits of teaching are the following (from most recorded to least recorded):

- learning and revision - improves knowledge $(n=15)$

- improves own skills $(n=5)$

- better patient care $(n=1)$

- increases experience $(n=1)$

- no benefits $(n=5)$.

\section{What hampers teaching?}

The registrars indicated the following as factors that hamper their teaching of UG students (from most recorded to least recorded):

- own workload $(n=10)$

- attitudes of students towards registrars $(n=7)$

- time constraints $(n=6)$

- anxiety and lack of training to teach $(n=3)$

- inexperience with regard to teaching $(n=2)$.

\section{Registrars' opinions regarding developing teaching skills}

Not one of the 25 registrars received any formal training in teaching. The majority ( $n=23$; $92 \%$ ) indicated that they deemed formal training in teaching necessary. Twenty-four registrars responded to the question as to whether they would be interested in a computer-based (e-learning-type training), with 16 (67\%) indicating 'yes'. Table 2 indicates the year of the registrarship in which the teaching should take place, and Table 3 depicts the time when the training should take place (as indicated by the registrars).

\section{Registrars assessment of students}

Table 4 indicates the involvement of registrars in the different methods of assessment. The majority of registrars are involved in more than one type of assessment $(n=16 ; 70 \%)$ (the

Table 2. Year of registrarship in which training should take place $(n=23)$

\begin{tabular}{ll}
\hline Year of registrarship & Respondents, $\boldsymbol{n}(\%)$ \\
\hline 1 & $16(70)$ \\
2 & $5(22)$ \\
3 & $2(8)$
\end{tabular}


Table 3. Time when training should take place, as suggested by registrars $(n=22)$

\begin{tabular}{ll}
\hline Time/day of training & Respondents, $\boldsymbol{n}(\%)$ \\
\hline One morning & $9(42)$ \\
One afternoon & $6(28)$ \\
Lunchtime & $2(10)$ \\
Evening & $2(10)$ \\
Saturday & $2(10)$
\end{tabular}

Table 4. Registrars' involvement in assessment

\begin{tabular}{ll}
\hline Type of assessment & $\begin{array}{l}\text { Respondents, } \\
\boldsymbol{n}(\%)\end{array}$ \\
\hline $\begin{array}{l}\text { Marking of written examinations } \\
\text { Objective structured clinical }\end{array}$ & $1(4)$ \\
examination & $2(9)$ \\
Signing off of logbooks & $4(17)$ \\
Multiple methods & $16(70)$
\end{tabular}

registrars marked more than one option in the table).

\section{Competencies necessary for registrars as teachers}

Ten competencies were included in a table; the registrars had to indicate their perceptions on the importance of the competency and rate themselves using the self-rated category with each of the competencies. This is summarised in Table 5. Values of 5 (high) to 1 (low) were indicated and the table summarises the score that the majority of the respondents indicated. All the registrars rated all the competencies as 5, with the importance of professionalism being the one most indicated. Not one self-rated ability obtained a score of 5 .

\section{Discussion}

The World Health Report of $2006^{[13]}$ emphasised the importance of training the correct number of quality healthcare workers; the quality of training medical practitioners in SA is clearly prescribed by the HPCSA. ${ }^{[1]}$ Essack, $^{[14]}$ in SA, reported that there is a severe shortfall in the existing and future personnel. A lay publication ${ }^{[15]}$ revealed that there must be an increase in the number of medical students to help to alleviate the shortage of doctors. However, who would ultimately be responsible for the added burden of teaching these students?

Our study, albeit a small pilot study, indicates that registrars do participate in the training of UG medical students, which concurs with the study conducted by Post et al. ${ }^{[3]}$ that showed

Table 5. Competencies with perceived importance and self-rated ability

\begin{tabular}{lll}
\hline Competency & $\begin{array}{l}\text { Perceived importance, } \\
\text { score }(\boldsymbol{n}(\%))\end{array}$ & $\begin{array}{l}\text { Self-rated ability, } \\
\text { score }(\boldsymbol{n}(\%))\end{array}$ \\
\hline Importance of being taught how to give a lecture & $5(10(44))$ & $3(11(46))$ \\
Teaching diagnostic skills & $5(18(79))$ & $4(9(38))$ \\
Teaching clinical procedures & $5(8(67))$ & $4(11(92))$ \\
Teaching patient management skills & $5(6(70))$ & $4(10(42))$ \\
Importance of providing feedback to students & $5(10(44))$ & $3(10(42))$ \\
Importance of assessment of students & $5(12(52))$ & $3(12(50))$ \\
Importance of attitudes and ethical values & $5(18(78))$ & $4(15(63))$ \\
Importance of professionalism & $5(18(82))$ & $4(13(54))$ \\
Importance of being a role-model & $5(17(74))$ & $4(16(67))$ \\
Ability of managing own stress & $5(15(75))$ & $4(17(74))$
\end{tabular}

registrars as having an important role in teaching clinical skills to students. In our study, most of the time spent on teaching was done during on-the-job and ward-round teaching. We could not accurately draw conclusions to the exact time registrars spend on teaching. They indicated that, on average, they worked 45 hours per week and all different types of teaching combined comprised 12.5 hours per week, i.e. nearly $30 \%$ of the work hours per week were spent on teaching - slightly more than the average of $20 \%$ reported by other authors, ${ }^{[4-8]}$ but less than the $40 \%$ reported by Smit. ${ }^{[2]}$

Our study also indicated that registrars generally have a positive attitude towards teaching. Only one registrar indicated that registrars should not teach, and another indicated that consultants should teach during the day and registrars after hours, during the on-call sessions. In our study, the perceived benefits of teaching were improving one's own knowledge and understanding of the topic. This was also reported by Weiss and Needlman, ${ }^{[9]}$ who stated that the knowledge obtained from teaching outweighed that acquired by self-study or attendance of lectures.

The AMEE Guide No. 20 includes on-thejob training as being part of a role-model. ${ }^{[10]}$ In our questionnaire, registrars indicated that they are occupied for $\sim 5$ hours 4 minutes per week with on-the-job-training. This type of training is generally done during on-call sessions (afterhours training). Although all competencies were regarded as important, teaching of clinical skills and professionalism received the highest ratings (Table 5).

Many of the registrars in our study take part in assessment of students. Norcini and Burch ${ }^{[1]}$ emphasised the importance of assessment in the workplace and the significance of providing feedback to students after the assessment to support learning. The registrars perceived providing feedback as important, but their self-rating on feedback received an average score of 3 . This suggests that they are of the opinion that they do not provide adequate feedback (the objective of the study was not to evaluate the quality of the feedback to UG students).

Not one of the registrars received formal training in teaching or assessment of UG students. In the USA, Morrison et al. ${ }^{[12]}$ indicated that by 2000 already $55 \%$ of residents were provided with instruction on teaching, although this was only 11 hours per resident for the entire residency. Only one registrar in our study indicated that no training in teaching is necessary. All the others indicated the need for training and that this should take part in the first year of the registrar training programme, preferably during a morning. The MEOP currently offered at UP is a 4-day course (4 afternoon sessions) and is not compulsory. The need for such training indicated by the small pilot study might motivate changing the current course and giving it during morning sessions, applicable specifically to registrars.

The major limitation of our study was the very small number of participants and that some did not respond to all the questions.

\section{Conclusion}

Our pilot study indicates that most of the registrars have a positive attitude towards teaching and that they spend approximately a third of their time on teaching UG students. Studies have shown that the knowledge obtained by teaching outweighs that obtained by self- 
study/attendance of lectures. An on-the-job role-model as part of teaching is very applicable to registrars; they can benefit from the teaching and assist in alleviating the teaching burden with the increase in medical students. The international literature indicates that, until recently, registrars were not offered a formal programme in teaching. Our study echoed this, and we suggest adapting such a programme to fulfil the needs of registrars. Our study comprised a very small number of registrars, and it would be beneficial to repeat the study at a forum, such as interdepartmental meetings, to attempt to obtain a better response rate.

Acknowledgement. The authors wish to express a special thank you to all the secretaries from the heads of department for the distribution of the questionnaires.

\section{References}

1. Health Professions Council of South Africa. Vision and Mission. Pretoria: HPCSA, 2013. http://www.hpcsa.co.za/ About/VisionMission (accessed 25 July 2016).

2. Smit EJ. Evaluation of a pilot 'registrar-as-a-teacher' faculty development program at Stellenbosch University. MPhil thesis Stellenbosch: Stellenbosch University, 2014. http://scholar.sun.ac.za/handle/10019.1/96044 (accessed 11 August 2016).
3. Post RE, Quattlebaum RG, Benich JJ. Residents-as-teachers curricula: A critical review. Acad Med 2009;84(3):374-380 DOI:10.1097/ACM.0b013e3181971ffe

4. Bing-You RG, Sproul WB. Medical students' perceptions of themselves and residents as teachers. Med Teach 1992;14(2-3):133-138. DOI:10.3109/01421599209079479

5. Morrison EH, Hollingshead J, Hubbell A, Hitchcock MA, Rucker L, Prislin MD. Reach out and teach someone Generalist residents' needs for teaching skills development. Fam Med 2002;34(6):445-450.

6. Greenberg LW, Goldberg RM, Jewett LS. Teaching in the clinical setting: Factors influencing residents perceptions, confidence and behaviour. Med Educ 1984;18(5):360-365. DOI:10.1111/i.1365-2923.1984. tb01283.x

7. Schenk TL, Sheets KJ, Marquez JT, Whitman NA, Davis WE, McClure CL. Where, how and from whom do family practice residents learn? A multi-centre analysis. Fam Med 1987;19(4):265-268.

8. Tremonti LP, Biddle WB. Teaching behaviours of residents and faculty members.Acad Med 1982:57(11):854-859. 8. Tremonti LP, Biddle WB. Teaching behavious

9. Weiss V, Needlman R. To teach is to learn twice: Resident teachers learn more. Arch Pediatr Adolesc Med 1998;152(2):190-192. DOI:10.1001/archpedi.152.2.190

10. Harden RM, Crossby J. AMEE Guide No. 20: The good teacher is more than a lecturer - the twelve roles of the teacher. Med Teach 2000;22(4):334-337. DOI:10.1080/014215900409429

11. Norcini J, Burch V. AMEE Guide No. 31: Workplace-based assessment as an educational tool. Med Teach 2007;29(9):855-871. DOI:10.1080/01421590701775453

12. Morrison EH, Friedland JA, Boker J, Rucker I, Hollingshead J, Murata P. Residents-as-teachers training in US residency programs and offices of graduate medical education. Acad Med 2001;76(10 Suppl):S1-S4 DOI:10.1097/00001888-200110001-00002

13. World Health Organization. Report. Working Together for Health. Geneva: WHO, 2006. http://www.who.int/ whr/2006/whr06_en.pdf (accessed 25 July 2016).

4. Essack SY. Models for increasing the health workforce. S Afr Med J 2012;102(11 Pt 1):830-832. DOI:10.7196/samj.5779

15. Rondganger L. SA needs 14351 doctors, 44780 nurses. IOL News. http://www.iol.co.za/dailynews/sa-needs-14 351-doctors-44-780-nurses-1.1456417 (accessed 25 January 2016). 